\title{
Effect of differing doses of inhaled budesonide on markers of airway inflammation in patients with mild asthma
}

\author{
Anon Jatakanon, Sergei Kharitonov, Sam Lim, Peter J Barnes
}

\begin{abstract}
Background-It is desirable to prescribe the minimal effective dose of inhaled steroids to control asthma. To ensure that inflammation is suppressed whilst using the lowest possible dose, a sensitive and specific method for assessing airway inflammation is needed.

Methods-The usefulness of exhaled nitric oxide (NO), sputum eosinophils, and methacholine airway responsiveness $\left(\mathbf{P C}_{20}\right)$ for monitoring airway inflammatory changes following four weeks of treatment with an inhaled corticosteroid (budesonide via Turbohaler) were compared. Mild stable steroid naive asthmatic subjects were randomised into two double blind, placebo controlled studies. The first was a parallel group study involving three groups receiving either $100 \mu \mathrm{g} / \mathrm{day}$ budesonide $(n=8), 400 \mu \mathrm{g} / \mathrm{day}$ budesonide $(n=7)$, or a matched placebo $(n=6)$. The second was a crossover study involving 10 subjects randomised to receive $1600 \mu \mathrm{g}$ budesonide or placebo. The groups were matched with respect to age, $\mathbf{P C}_{20}$, baseline $\mathrm{FEV}_{1}$ (\% predicted), exhaled NO, and sputum eosinophilia.
\end{abstract}

Results-There were significant improvements in $\mathrm{FEV}_{1}$ following $400 \mu \mathrm{g}$ and $1600 \mu \mathrm{g}$ budesonide $(11.3 \%$ and $6.5 \%$, respectively, $\mathrm{p}<0.05)$. This was accompanied by significant reductions in eosinophil numbers in induced sputum $(0.7$ and 0.9 fold, $p<0.05)$. However, levels of exhaled NO were reduced following each budesonide dose while $\mathbf{P C}_{20}$ was improved only with $1600 \mu \mathrm{g}$ budesonide. These results suggest that exhaled $\mathbf{N O}$ and $\mathbf{P C}_{20}$ may not reflect the control of airway inflammation as accurately as the number of eosinophils in sputum. There were dose dependent changes in exhaled NO, sputum eosinophils, and $\mathbf{P C}_{20}$ to inhaled budesonide but a plateau response of exhaled NO was found at a dose of $400 \mu \mathrm{g}$ daily.

Conclusion-Monitoring the number of eosinophils in induced sputum may be the most accurate guide to establish the minimum dose of inhaled steroids needed to control inflammation. This, however, requires further studies involving a larger number of patients.

(Thorax 1999;54:108-114)

Keywords: asthma; inhaled corticosteroids; airway inflammation
Inhaled glucocorticoids are the most effective therapy currently available for the treatment of chronic asthma. They are now recommended for asthmatic patients who have symptoms more than twice a week ${ }^{1}$ or require an inhaled $\beta_{2}$ agonist more than once daily. ${ }^{2}$ High dose inhaled steroids are recommended for the treatment of more severe asthma. Once the disease is under control, the dose of inhaled steroids should be stepped down to the minimum dose that maintains control. ${ }^{12}$

Assessment of asthma control is usually based on frequency of symptoms, the need for rescue short acting inhaled $\beta_{2}$ agonists, and measurements of lung function such as peak expiratory flow (PEF) and forced expiratory volume in the first second $\left(\mathrm{FEV}_{1}\right) .{ }^{12}$ Treatment is aimed at maintaining optimum lung function with no or very minimal symptoms and little need for rescue inhaled $\beta_{2}$ agonist. Based on these treatment guidelines, however, complete suppression of airway inflammation may not be achieved. ${ }^{3}$ It is not current clinical practice to determine whether airway inflammation is maximally suppressed and whether the maintenance dose of inhaled steroids is the optimum dose for the control of airway inflammation in an individual patient. Yet it has been postulated that inadequate treatment of airway inflammation may lead to irreversible changes in airway function. ${ }^{4}$

More direct and sensitive measurements of airway inflammation are required to detect subclinical airway inflammation which may persist due to inadequate treatment or recur when the dose of inhaled corticosteroids is stepped down. The methods of measurement should be objective, performed easily, be reproducible, reliable, and non-invasive. To this end there is evidence to suggest that monitoring the level of exhaled nitric oxide (NO) and the number of eosinophils in induced sputum could be useful. Both are increased in asthma ${ }^{5}{ }^{6}$ but the increased levels are decreased following corticosteroid treatment. ${ }^{7-9}$

The aim of our study was to compare the usefulness of exhaled NO, sputum eosinophils, and airway responsiveness to methacholine for monitoring airway inflammation. We also wanted to investigate whether inhaled steroids can modulate exhaled NO, sputum eosinophils, and airway responsiveness in a dose dependent manner.

\section{Methods}

PATIENTS

Non-smoking stable allergic asthmatic patients who required only short acting $\beta_{2}$ agonist 
(salbutamol) therapy on demand were recruited into the study. Stable asthma was defined as no changes in asthma symptoms and asthma medications in the previous month. Patients were required to have a prebronchodilator $\mathrm{FEV}_{1}$ of $\geqslant 80 \%$ predicted without a history of corticosteroid treatment or an exacerbation of asthma within the previous three months. Allergic status was defined by the presence of a positive skin prick test to at least one of four common aeroallergens (grass pollen, cat dander, Dermatophagoides pteronyssinus, Aspergillus fumigatus). All patients gave a history of intermittent wheezing and chest tightness and had previously been diagnosed by a physician as having asthma. Patients had a provocative concentration of methacholine producing a $20 \%$ fall in $\mathrm{FEV}_{1}\left(\mathrm{PC}_{20}\right)$ of $\leqslant 4 \mathrm{mg} / \mathrm{ml}$. Exclusion criteria included a history of upper respiratory tract infection within six weeks of the start of the study and treatment with nasal steroids within the previous two months. The study protocol was approved by the ethics committee of the Royal Brompton Hospital.

PROTOCOLS

Inflammation within the airways was reduced by giving inhaled budesonide via a dry powder inhaler device (Turbohaler) at a dose of $100 \mu \mathrm{g}$ (minimum), $400 \mu \mathrm{g}$ (medium), and $1600 \mu \mathrm{g}$ (maximum) to mild asthmatic subjects (fourfold different doses). This allowed us to compare the changes in exhaled NO, sputum eosinophils, and $\mathrm{PC}_{20}$ in relation to the changes in lung function. At the same time we were able to determine whether inhaled budesonide inhibited these inflammatory markers in a dose dependent manner. The budesonide dose of $100 \mu \mathrm{g}$ had to be given as one puff daily while, in those with mild to moderate stable asthma, the $400 \mu \mathrm{g}$ dose could be given as either once daily or two divided doses. ${ }^{10}$ The maximum recommended dose of $1600 \mu \mathrm{g}$ daily was given as two divided doses in order to obtain the maximum benefit with minimal side effects. Although a double parallel group study involving the three different doses of budesonide could be accomplished with added placebo, it would be complicated, requiring four Turbohaler devices for each subject. At this time we were conducting a double blind crossover study (high dose budesonide study) using budesonide Turbohaler $1600 \mu \mathrm{g}$ daily or a matching placebo to determine the maximum benefit of budesonide on airway inflammation. This allowed us to use the data obtained before and after budesonide treatment to demonstrate its maximum effect. We then conducted another study to evaluate the effects of budesonide at lower doses (low dose budesonide study) and analysed the data from both studies together to compare the three different daily doses of budesonide. Based on the standard deviation of exhaled NO in mild asthma being $6 \mathrm{ppb}$, eight subjects were required in each budesonide treatment arm to detect the changes in exhaled NO of $9 \mathrm{ppb}$ within group for an alpha specification of 0.05 and a beta specification of 0.20 ( $80 \%$ power).
The low dose budesonide study was a double blind randomised parallel group study. This involved three parallel groups of patients with mild asthma who received either 100 or $400 \mu \mathrm{g}$ of budesonide Turbohaler or a matching placebo given via a Turbohaler as one puff daily. Following a one week run in period the patients were randomised to receive either placebo or budesonide Turbohaler for four weeks. Six and eight patients were required for the placebo and each budesonide treatment group, respectively. $\mathrm{FEV}_{1}$, exhaled $\mathrm{NO}, \mathrm{PC}_{20}$, and sputum eosinophil numbers were measured before randomisation and at the end of each treatment period.

The high dose budesonide study involved mild asthmatic subjects with the same inclusion and exclusion criteria. Patients were randomised to receive either budesonide $1600 \mu \mathrm{g}$ daily (via Turbohaler, $400 \mu \mathrm{g} /$ puff given as two puffs twice daily) or matching placebo for four weeks in a double blind crossover fashion. The washout period was four weeks. $\mathrm{FEV}_{1}$, exhaled NO, $\mathrm{PC}_{20}$, and sputum eosinophil numbers were measured before and after each treatment period. Ten subjects were recruited and randomly allocated to receive either budesonide first $(n=5)$ or placebo first $(n=5)$.

In both studies subjects recorded morning and evening peak expiratory flow rate (PEF, best of three), symptom scores, and the amount of rescue inhaled $\beta_{2}$ agonist (puffs per day) throughout the study period. Symptom scores were measured as asthma during the day, asthma during the night, and early morning tightness, ranging from $0-3$ for each item $(0=$ none, $1=$ mild, $2=$ moderate, $3=$ severe $)$.

LUNG FUNCTION

$\mathrm{FEV}_{1}$ and FVC were measured with a dry spirometer (Vitalograph, Buckingham, UK). The best value of the three manoeuvres was expressed as a percentage of the predicted value. Morning and evening peak flow were measured using a mini-Wright peak flow meter (Clement Clarke International Ltd, Harlow, $\mathrm{UK})$.

AIRWAY RESPONSIVENESS

Airway responsiveness was measured by methacholine challenge with doubling concentrations of methacholine $(0.06-32 \mathrm{mg} / \mathrm{ml})$ delivered by dosimeter ${ }^{11}$ (Mefar, Bovezzo, Italy) with an output of $10 \mu \mathrm{l}$ per inhalation. The aerosols were inhaled at tidal breathing while wearing a nose clip. A total of five inhalations of each concentration was administered (inhalation time one second, breath holding time six seconds). $\mathrm{FEV}_{1}$ was measured two minutes after the last inhalation until there was a fall in $\mathrm{FEV}_{1}$ of $\geqslant 20 \%$ compared with the control inhalation $(0.9 \%$ saline solution) or until the maximal concentration was inhaled. The $\mathrm{PC}_{20}$ was calculated by interpolation of the logarithmic dose response curve.

MEASUREMENT OF EXHALED NO

End exhaled NO was measured by a chemiluminescence analyser (Model LR2000, Logan 
Research, Rochester, UK) sensitive to NO from 1 to 5000 parts per billion (ppb, by volume) using a previously described method. ${ }^{12}$ In brief, subjects exhaled slowly at a flow rate of $5-61 / \mathrm{min}$ from total lung capacity over $30-40 \mathrm{~s}$ through a mouthpiece. NO was sampled at $250 \mathrm{ml} / \mathrm{min}$ from a side arm attached to the mouthpiece. The measurement was taken from the point corresponding to the plateau of end exhaled $\mathrm{CO}_{2}\left(5-6 \% \mathrm{CO}_{2}\right)$ and represents the lower respiratory tract sample. Results of the analyses were computed and graphically displayed on a plot of $\mathrm{NO}$ and $\mathrm{CO}_{2}$ concentration, pressure and flow against time.

SPUTUM INDUCTION AND PROCESSING

Sputum was collected using the method previously described by Keatings et al. ${ }^{8}$ Subjects were instructed to wash their mouths thoroughly with water prior to induction. They then inhaled $3.5 \%$ saline at room temperature, nebulised via an ultrasonic nebuliser (DeVilbiss 99; DeVilbiss, Heston, UK) at maximum output for 15 minutes. Subjects were encouraged to cough deeply at five and three minute intervals thereafter. Sputum was collected into a polypropylene pot and saliva was discarded into a bowl. Following sputum induction the spirometric measurements were repeated. If $\mathrm{FEV}_{1}$ had fallen, the subject was required to wait until it had returned to the baseline value. Sputum samples were kept at $4^{\circ} \mathrm{C}$ for not more than two hours before further processing.

The volume of sample was recorded and the sputum was diluted with $2 \mathrm{ml}$ of Hanks' balanced salt solution (HBSS) containing 1\% dithiothreitol (DTT; Sigma Chemicals, Poole, $\mathrm{UK})$, periodically aspirated through a small bore pipette and vortexed. When homogeneous, samples were further diluted with HBSS, vortexed briefly, and left at room temperature for five minutes. They were then spun at $300 \mathrm{~g}$ for 10 minutes and the cell pellet was resuspended with HBSS. Total cell counts were done on a haemacytometer using Kimura stain and slides were made with a cytospin (Shandon, Runcorn, UK) and stained with MayGrunwald-Giemsa stain for differential cell counts which were performed by an observer blind to the clinical characteristics of the

Table 1 Baseline lung function and markers of airway inflammation in the four groups of asthmatic patients studied

\begin{tabular}{|c|c|c|c|c|c|c|c|c|}
\hline & \multicolumn{6}{|c|}{ Low dose budesonide study } & \multicolumn{2}{|c|}{$\begin{array}{l}\text { High dose } \\
\text { budesonide } \\
\text { study }\end{array}$} \\
\hline & \multicolumn{2}{|l|}{ Placebo } & \multicolumn{2}{|l|}{$100 \mu g$} & \multicolumn{2}{|c|}{$400 \mu g$} & \multicolumn{2}{|c|}{$1600 \mu g$} \\
\hline No. of patients & 6 & & 8 & & 7 & & 10 & \\
\hline Sex & $6 \mathrm{M}$ & & $8 \mathrm{M}$ & & $7 \mathrm{M}$ & & $8 \mathrm{~F} / 2 \mathrm{M}$ & \\
\hline Age (years) & 31 & $(2.8)$ & 31 & $(1.2)$ & 29 & $(2.4)$ & 29 & $(1.2)$ \\
\hline $\mathrm{FEV}_{1}(\%$ predicted $)$ & 97.2 & $(4.0)$ & 92.3 & (3.1) & 91.5 & $(4.2)$ & 96.2 & (3.1) \\
\hline Morning PEF (1/min) & 552 & (32) & 512 & (20) & 501 & (19) & 461 & (33) \\
\hline PEF variability (\%) & 10.7 & $(1.8)$ & 11.9 & (2.7) & 16.7 & $(2.8)$ & 9.3 & (1.3) \\
\hline Symptom scores & 1.0 & $(0.4)$ & 1.0 & $(0.3)$ & 1.0 & $(0.4)$ & 0.7 & $(0.2)$ \\
\hline Rescue inhaler (puff/day) & 0.9 & $(0.4)$ & 0.8 & $(0.3)$ & 1.0 & $(0.3)$ & 0.6 & $(0.2)$ \\
\hline $\mathrm{PC}_{20}(\mathrm{mg} / \mathrm{ml})$ & 0.46 & (1.61) & 0.47 & $(1.41)$ & 0.51 & $(1.20)$ & 0.67 & $(1.42)$ \\
\hline Exhaled NO (ppb) & 27.2 & (3.5) & 28.8 & $(2.4)$ & 31.8 & $(4.1)$ & 40.9 & $(7.2)$ \\
\hline Sputum eosinophils ${ }^{1}(\%)$ & 1.9 & $(8.2)$ & 4.9 & $(8.0)$ & 3.5 & (3.2) & 2.2 & (8.7) \\
\hline
\end{tabular}

Mean (SE) values are shown except ${ }^{1}$ median value (interquartile range).

$\mathrm{FEV}_{1}=$ forced expiratory volume in one second $\mathrm{PEF}=$ peak expiratory flow; $\mathrm{PC}_{20}=$ provocative concentration of methacholine causing a $20 \%$ drop in $\mathrm{FEV}_{1} ; \mathrm{NO}=$ nitric oxide; $\mathrm{ppb}=$ parts per billion. subjects. At least 500 inflammatory cells were counted in each subject. The reproducibility of differential cell counts in our laboratory involving 20 pairs of samples collected from stable asthmatic subjects during a two week period showed intra-class correlation coefficients of 0.75 for eosinophils, 0.78 for neutrophils, 0.76 for macrophages, and 0.56 for lymphocytes. ${ }^{13}$

\section{STATISTICAL ANALYSIS}

Data were expressed as the arithmetic mean (SE) apart from $\mathrm{PC}_{20}$ data which were log transformed and reported as geometric mean (SE) and sputum eosinophils which were expressed as median (interquartile range). The mean values of morning PEF, PEF variability (amplitude \% max), total symptom scores, and reliever inhaler use (puffs/day) from the seven day run in period and the last seven days of the treatment period were calculated.

To evaluate the roles of exhaled $\mathrm{NO}$ and sputum eosinophils in monitoring the changes in airway inflammation following treatment with $100 \mu \mathrm{g}$ and $400 \mu \mathrm{g}$ budesonide and placebo, either a paired sample $t$ test or Wilcoxon test was used for determining the treatment effect within groups for parametric data or non-parametric data, respectively. Changes in sputum eosinophil numbers, exhaled NO levels, $\mathrm{PC}_{20}$, and $\mathrm{FEV}_{1}$ after treatment were compared between treatments by one way ANOVA with the Kruskal-Wallis test or an equivalent. Either Bonferroni correction (parametric data) or Dunn's multiple comparison test (non-parametric data) was used to examine paired differences. The effect of high dose $1600 \mu \mathrm{g}$ budesonide treatment was examined by using the standard method of analysis recommended for crossover studies. ${ }^{14}$ Two tailed tests were performed and a $\mathrm{p}$ value of less than 0.05 was considered significant.

To evaluate the dose dependent response of budesonide on non-invasive markers of airway inflammation such as sputum eosinophil numbers, exhaled $\mathrm{NO}$, and $\mathrm{PC}_{20}$, only the data collected before and after four weeks of treatment with 100,400 , and $1600 \mu \mathrm{g}$ budesonide from both studies were combined for analysis. The changes from baseline before treatments were determined and analysed for a trend towards greater change with a higher dose of budesonide using a non-parametric method to test for trend across the groups. ${ }^{15}$

\section{Results}

PATIENTS

The characteristics of the patients at baseline from both studies are summarised in table 1 . One patient who was receiving $400 \mu \mathrm{g}$ budesonide was excluded from analysis because infection of the upper respiratory tract developed during the study. There were no significant differences between the groups in baseline $\mathrm{FEV}_{1}$, morning PEF, PEF variability, $\mathrm{PC}_{20}$, exhaled $\mathrm{NO}$, eosinophil counts in induced sputum, symptom scores, or daily $\beta_{2}$ agonist use. 
Table 2 Effects of inhaled budesonide treatment on markers of airway inflammation and lung function

\begin{tabular}{|c|c|c|c|c|c|c|c|c|c|}
\hline & \multicolumn{4}{|c|}{ Low dose budesonide study } & \multicolumn{5}{|c|}{ High dose budesonide study } \\
\hline & Placebo & $\begin{array}{l}100 \mu g \\
\text { budesonide }\end{array}$ & $\begin{array}{l}400 \mu g \\
\text { budesonide }\end{array}$ & $p$ value ${ }^{*}$ & $\begin{array}{l}\text { Difference } \neq \\
(\text { Bud-Pla) }\end{array}$ & $\begin{array}{l}\text { Difference } \neq \\
(\text { Pla-Bud) }\end{array}$ & $p$ value $(95 \% C I)^{\star *}$ & Placebo & $\begin{array}{l}1600 \mu \mathrm{g} \\
\text { budesonide }\end{array}$ \\
\hline$\Delta \mathrm{FEV}_{1}(1 / \mathrm{min})$ & $-0.2(0.1)$ & $0.0(0.1)$ & $0.5(0.2)$ & & $0.2(0.0)$ & $-0.4(0.2)$ & $<0.05(0.1$ to 0.9$)$ & $-0.1(0.1)$ & $0.2(0.1)$ \\
\hline$\%$ change & $-5.8(2.4)$ & $1.2(1.9)$ & $11.3(4.3)$ & $<0.05 \dagger$ & & & & $-2.8(2.1)$ & $6.5(3.2)$ \\
\hline$\Delta$ morning PEF $(1 / \mathrm{min})$ & $-17(10)$ & $20(5)$ & $36(14)$ & & $26(11)$ & $-23(16)$ & $<0.05$ ( 2 to 95$)$ & $-3.5(9.9)$ & $26(9)$ \\
\hline$\%$ change & $-2.9(1.7)$ & $4.1(1.2)$ & $7.3(2.8)$ & $<0.05 t$ & & & & $-0.4(2.0)$ & $5.9(2.3)$ \\
\hline$\Delta \mathrm{PEF}$ variability (\%) & $5.7(2.7)$ & $-1.4(1.3)$ & $-4.7(1.5)$ & $<0.01$ & $-1.8(3.5)$ & $1.3(2.3)$ & NS & $0.0(2.5)$ & $-1.9(1.7)$ \\
\hline$\Delta$ Symptom scores & $0.1(0.5)$ & $-0.4(0.2)$ & $-1.1(0.2)$ & $<0.05$ & $0.0(0.3)$ & $0.0(0.6)$ & NS & $0.0(0.1)$ & $0.1(0.3)$ \\
\hline$\Delta$ Rescue inhaler (puff/day) & $0.6(0.2)$ & $-0.5(0.3)$ & $-0.9(0.3)$ & $<0.01$ & $-0.2(0.2)$ & $0.1(0.9)$ & NS & $0.2(0.2)$ & $0.2(0.3)$ \\
\hline$\Delta \mathrm{PC}_{20}(\mathrm{mg} / \mathrm{ml})^{1}$ & $-0.69(2.00)$ & $1.01(1.57)$ & $1.31(1.51)$ & NS & $8.71(1.54)$ & $0.16(1.65)$ & $<0.001(0.003$ to 0.089$)$ & $-0.68(1.38)$ & $6.57(1.50)$ \\
\hline Fold change in $\log \mathrm{PC}_{20}$ & $-0.3(1.4)$ & $0.3(1.3)$ & $0.3(2.2)$ & & & & & $-1.0(0.8)$ & $2.8(1.0)$ \\
\hline$\Delta$ Exhaled NO (ppb) & $1.5(3.8)$ & $-8.2(2.7)$ & $-19.2(5.0)$ & & $-2.4(6.4)$ & $-22.5(6.3)$ & $0.07(-50.2$ to 2.2$)$ & $-3.5(3.4)$ & $-22.5(6.3)$ \\
\hline Fold change & $0.1(0.1)$ & $-0.2(0.1)$ & $-0.6(0.1)$ & $<0.05 \dagger$ & & & & $0.0(0.1)$ & $-0.5(0.1)$ \\
\hline $\begin{array}{l}\Delta \text { Sputum eosinophil } \\
\text { number }(\%)^{2}\end{array}$ & $1.4(9.2)$ & $-3.5(6.4)$ & $-1.7(5.4)$ & & $-0.2(2.8)$ & $4.0(4.9)$ & $<0.05(-8.1$ to -2.0$)$ & $-0.5(3.8)$ & $-2.0(7.6)$ \\
\hline Fold change $^{2}$ & $3.7(5.1)$ & $-0.6(3.8)$ & $-0.7(0.6)$ & $<0.05 \dagger$ & & & & $-0.3(2.2)$ & $-0.9(0.4)$ \\
\hline
\end{tabular}

Abbreviations as in table 1.

Mean (SE) values are shown except ${ }^{1}$ geometric mean (geometric SE), ${ }^{2}$ median (interquartile range).

${ }^{\star}$ Significant difference between three treatment groups by one way ANOVA or Kruskal-Wallis test.

+Percentage or fold changes from baselines were used for comparisons.

\#ifferences between the values measured at the end of first treatment period (either budesonide or placebo) subtracted by the same values measured at the end of the second treatment period (either placebo or budesonide): each value indicates the average or median change from baseline in five subjects who received budesonide first followed by placebo (Bud-Pla) and vice versa (Pla-Bud).

$\star \star$ Treatment effects obtained by comparing the differences between (Bud-Pla) and (Pla-Bud).

\Geometric CI.

TSummarises the changes from baseline in 10 subjects.

LOW DOSE BUDESONIDE STUDY

Exhaled NO levels were significantly reduced following both $100 \mu \mathrm{g}$ budesonide (from 28.8 to $20.6 \mathrm{ppb}$ ) and $400 \mu \mathrm{g}$ budesonide (from 31.8 to $15.8 \mathrm{ppb}$ ) but remained unchanged following placebo treatment (from 27.2 to 28.7 $\mathrm{ppb}$ ). Within each treatment comparison there were significant reductions following treatment with both $100 \mu \mathrm{g}$ ( $\mathrm{p}<0.05,95 \%$ CI 1.7 to $14.5)$ and $400 \mu \mathrm{g}(\mathrm{p}<0.01,95 \%$ CI 6.9 to 31.4) budesonide. The mean fold changes from baseline were $-0.2,-0.6$, and 0.1 following $100 \mu \mathrm{g}, 400 \mu \mathrm{g}$ budesonide and placebo, respectively. Between treatment comparison showed a significant difference only between the placebo and $400 \mu \mathrm{g}$ budesonide groups $(\mathrm{p}<0.01,95 \% \mathrm{CI}-1.1$ to -0.3 , table 2 , fig $1 \mathrm{~A}$, left panel).

There was a reduction in the median number of sputum eosinophils following both $100 \mu \mathrm{g}$ budesonide (from $4.9 \%$ to $1.5 \%$ ) and $400 \mu \mathrm{g}$ budesonide (from $3.5 \%$ to $1.0 \%$ ) but the eosinophil number was increased following placebo treatment (from $1.9 \%$ to $5.2 \%$ ). Within each treatment comparison there was only a significant reduction after $400 \mu \mathrm{g}$ budesonide ( $p<0.05,95 \%$ CI 0.3 to 3.8 ). The median fold changes from baseline were -0.6 , -0.7 , and 3.7 after $100 \mu \mathrm{g}$ budesonide, $400 \mu \mathrm{g}$ budesonide and placebo, respectively. Between treatment comparisons demonstrated a significant difference between the placebo and $400 \mu \mathrm{g}$ budesonide groups $(\mathrm{p}<0.05,95 \% \mathrm{CI}$ 0.2 to 5.8 , table 2 , fig $1 \mathrm{~B}$, left panel).

$\mathrm{FEV}_{1}$ was increased following treatment with both $100 \mu$ g budesonide (from 3.8 to 3.9 l) and $400 \mu \mathrm{g}$ budesonide (from 4.1 to $4.6 \mathrm{l}$ ) but decreased in the placebo treated group (from 4.0 to 3.71 ). The mean percentage increases in $\mathrm{FEV}_{1}$ were $1.2 \%, 11.3 \%$, and $-5.8 \%$ following $100 \mu \mathrm{g}$ budesonide, $400 \mu \mathrm{g}$ budesonide and placebo, respectively. Within each treatment comparison there was a significant improvement only after $400 \mu \mathrm{g}$ budesonide $(\mathrm{p}<0.05$, $95 \%$ CI -0.9 to -0.1 ). Comparison between treatments showed a significant difference between placebo and $400 \mu \mathrm{g}$ budesonide treatment only ( $\mathrm{p}<0.01,95 \%$ CI -29.0 to -5.3 , table 2, fig 2A, left panel). Similarly, morning PEF was significantly increased following treatment with $400 \mu \mathrm{g}$ budesonide compared
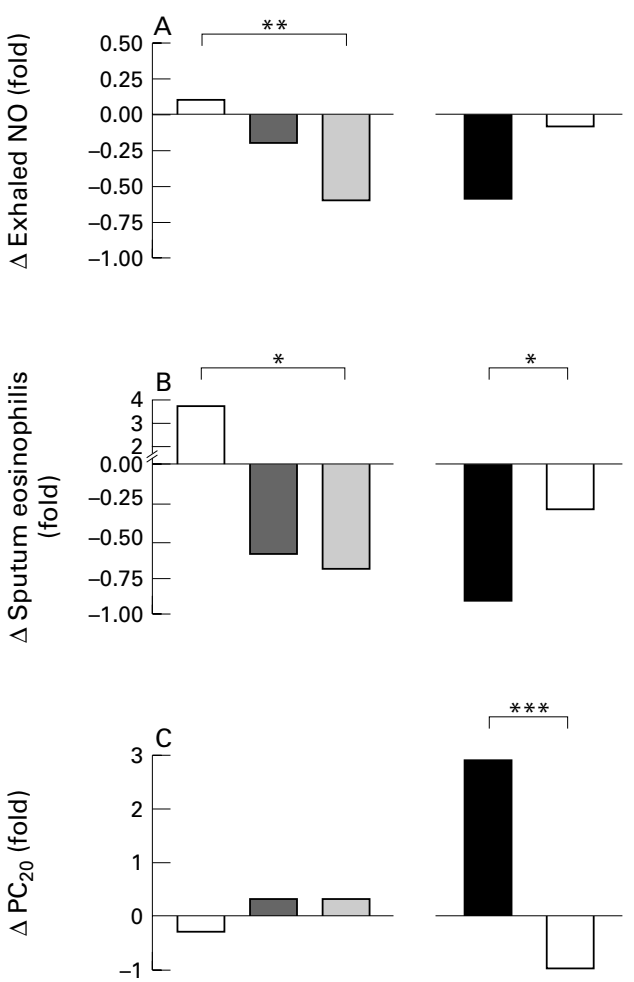

Figure 1 Changes in $(A)$ exhaled nitric oxide (NO), (B) sputum eosinophil numbers, and (C) methacholine airway responsiveness in the low dose budesonide study (left panel) and high dose budesonide study (right panel). Each bar represents the mean changes from baseline, except the change in sputum eosinophils represents the median change from baseline. $P C_{20}$ indicates the change in geometric mean value. White bars indicate placebo treatment, shaded bars indicate treatment with $100 \mu \mathrm{g}$ budesonide (dark shading) and $400 \mu \mathrm{g}$ budesonide (light shading), solid bars indicate treatment with $1600 \mathrm{mg}$ budesonide. ${ }^{\star} p<0.05 ;{ }^{\star}{ }^{*}<0.01$; $\star \star \star x<0.001$ for differences between groups. 


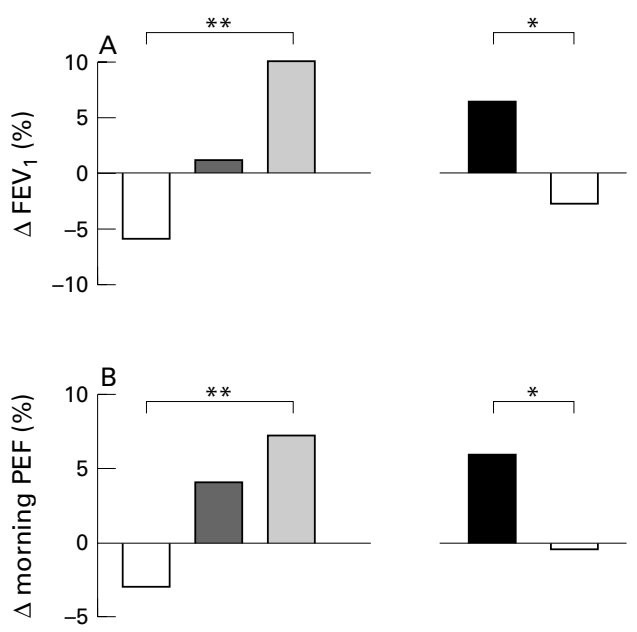

Figure 2 Changes in (A) forced expiratory volume in one second (FEV) and $(B)$ morning peak expiratory flow (PEF) in the low dose budesonide study (left panel) and high dose budesonide study (right panel). Each bar represents the mean changes from baseline. White bars indicate placebo treatment, shaded bars indicate treatment with $100 \mu \mathrm{g}$ budesonide (dark shading) and $400 \mu \mathrm{g}$ budesonide (ight shading), solid bars indicate treatment with 1600 mg budesonide. ${ }^{\star} p<0.05,{ }^{\star} p<0.01$ for differences between groups.

with placebo ( $\mathrm{p}<0.01,95 \% \mathrm{CI}-17.8$ to -2.7 , table 2, fig 2B). Furthermore, there were significant decreases in PEF variability $(\mathrm{p}<0.01,95 \% \mathrm{CI}-17.5$ to -3.20$), \beta_{2}$ agonist requirement $(\mathrm{p}<0.01,95 \% \mathrm{CI}-2.7$ to -0.3$)$, and total symptom scores $(\mathrm{p}<0.05,95 \% \mathrm{CI}$ -2.3 to -0.1 ) following treatment with $400 \mu \mathrm{g}$ budesonide compared with placebo.

There was no change in $\mathrm{PC}_{20}$ either within or between groups of budesonide and placebo treatments.

HIGH DOSE BUDESONIDE STUDY

Neither carryover nor period effects of lung function were found on markers of airway inflammation. Treatment effects of budesonide on exhaled NO, sputum eosinophils, $\mathrm{PC}_{20}$, $\mathrm{FEV}_{1}$, and morning PEF were then examined and are summarised in table 2 and figs 1 and 2 (right panels). The results indicated decreases in both sputum eosinophil number (from 2.2 to 0.2 ) and airway hyperresponsiveness following treatment with $1600 \mu \mathrm{g}$ budesonide. There was also an increase in both $\mathrm{FEV}_{1}$ and morning PEF. Exhaled NO levels were markedly decreased but this failed to reach a significant level $(\mathrm{p}=0.07)$.

DOSE RESPONSIVENESS OF AIRWAY INFLAMMATORY MARKERS TO INHALED BUDESONIDE

Exhaled NO levels were reduced from 40.9 (7.2) to 18.4 (3.6) $\mathrm{ppb}$ following four weeks of treatment with $1600 \mu \mathrm{g}$ budesonide. The mean change (fold) in exhaled NO levels from baseline were $-0.2,-0.6$, and -0.5 following treatment with 100,400 , and $1600 \mu \mathrm{g}$ budesonide, respectively. Analysis for a trend across the three groups failed to demonstrate greater reductions in exhaled NO with increasing doses of budesonide. This indicates a dose dependent reduction of exhaled NO in re- sponse to low dose steroids with a plateau response to the higher dose (fig 1A).

There were reductions in sputum eosinophil numbers from $2.2(8.7) \%$ to 0.2 (1.5)\% following the four week treatment with $1600 \mu \mathrm{g}$ budesonide. The median change (fold) in sputum eosinophil number following 100, 400, and $1600 \mu \mathrm{g}$ budesonide were $-0.6,-0.7$, and -0.9 , respectively. Analysis for a trend across the groups showed a significant trend towards more reduction in sputum eosinophils with increasing doses of budesonide $(p<0.05)$. This suggested a greater reduction in sputum eosinophil numbers with increasing dose of inhaled budesonide (fig 1B).

With the treatment period of four weeks the increases in $\mathrm{PC}_{20}$ (geometric mean, $\mathrm{mg} / \mathrm{ml}$ ) from baseline following treatment with 100, 400 , and $1600 \mu \mathrm{g}$ budesonide were 1.01 (1.57), 1.31 (1.51), and 6.57 (1.50), respectively. Analysis for a trend across the groups demonstrated a greater improvement in $\mathrm{PC}_{20}$ with increasing doses of budesonide $(p<0.01$; fig 1C).

\section{Discussion}

In this composite study we have shown that monitoring exhaled $\mathrm{NO}$ and sputum eosinophils may be useful in the assessment of airway inflammatory changes following inhaled corticosteroid treatment. There were dose dependent changes in sputum eosinophils and $\mathrm{PC}_{20}$ to inhaled budesonide, with the maximum reduction at the highest dose. Exhaled NO levels were also decreased in a dose dependent manner but the maximum suppression was reached with the medium dose of budesonide.

We have shown that the use of budesonide in a daily dose of $100 \mu \mathrm{g}$ led to a significant reduction in exhaled NO levels compared with baseline, yet there was no significant change in lung function and other non-invasive markers of inflammation such as sputum eosinophilia and $\mathrm{PC}_{20}$. Although it is possible that a significant reduction in sputum eosinophil numbers would have been statistically significant if a larger number of subjects had been included, this suggests that NO may be more sensitive to low doses of inhaled steroids. A reduction in exhaled NO following treatment with inhaled corticosteroids may not therefore necessarily reflect a control of airway inflammation and needs to be confirmed by more direct measurements such as sputum eosinophil number. Our data have shown a dose dependent effect on exhaled NO, as budesonide $400 \mu \mathrm{g}$ was more effective in reducing $\mathrm{NO}$ than budesonide $100 \mu \mathrm{g}$. However, there was no further reduction with the dose of $1600 \mu \mathrm{g}$, possibly due to a plateau response of exhaled NO to higher doses of inhaled steroids. This plateau in response of exhaled NO, in the face of further changes in other inflammatory markers such as sputum eosinophils and $\mathrm{PC}_{20}$, may limit the clinical usefulness of exhaled $\mathrm{NO}$ as an accurate marker for monitoring asthma control as it may be too sensitive to inhaled corticosteroids. However, it needs to be emphasised that only 
mild steroid naive asthmatic subjects were studied.

Sputum induction has been advocated as a non-invasive alternative for measuring airway inflammation with greater advantage in terms of reproducibility and simplicity. ${ }^{16-18}$ The number of eosinophils in sputum has been found to correlate with asthma severity. ${ }^{19}$ Eosinophil numbers are increased in both mild and severe exacerbations of asthma, ${ }^{20}{ }^{21}$ but they are decreased with corticosteroid treatment in association with an improvement in lung function. ${ }^{21}$ This affirms the potential value of sputum eosinophils as an objective marker for assessing the control of asthma. Our study supports this conclusion, as a significant reduction in sputum eosinophils was found only in association with a significant improvement in $\mathrm{FEV}_{1}$. In contrast, there was an increase in sputum eosinophils in association with poor asthma control in placebo treated patients. This suggests that there is persistent variable eosinophilic inflammation within the airways of asthmatic subjects not treated with inhaled steroids. If airway inflammation is not monitored, this unrecognised inflammation might lead to irreversible airway damage over time. The inhibitory effect of corticosteroids on sputum eosinophils could be due to an inhibitory effect of steroids to the permissive action of cytokines such as granulocytemacrophage colony stimulating factor (GMCSF) or interleukin-5 (IL-5) on eosinophil survival, ${ }^{22-24}$ a reduction in circulating eosinophil numbers, ${ }^{25}$ and a reduction in the concentration of IL-5 in sputum ${ }^{21}$ and blood. ${ }^{26}$

There is clinical evidence to suggest that inhaled steroids improve asthma control in a dose related manner ${ }^{27}$ and high dose inhaled steroids are recommended for more severe asthma. ${ }^{12}$ However, no clear dose response effect of inhaled steroids on airway inflammation has yet been demonstrated. This may be due to the heterogeneity of patients recruited, the varying degree of airway drug deposition, or lack of available sensitive methods for measuring airway inflammation. Our mild asthmatic subjects had the same clinical severity by conventional markers of asthma severity such as lung function, peak flow variation, and asthma symptom scores. Moreover, they had the same basal levels of airway inflammation reflected by sputum eosinophil numbers, $\mathrm{PC}_{20}$, and exhaled NO levels. In this study we have shown a significant trend towards greater reduction in sputum eosinophils with higher dose budesonide, suggesting a dose dependent effect of inhaled steroids on eosinophilic airway inflammation. It remains to be established whether in mild asthma the differing dose schedules may partly account for a greater effect of the higher doses of budesonide. The studies in patients with mild to moderately severe asthma, however, indicate that budesonide Turbohaler $400 \mu \mathrm{g}$ and $800 \mu \mathrm{g}$ given once daily provide improvements in lung function to the same level as the same total daily dose given twice daily. ${ }^{10}{ }^{28}$ It is also possible that budesonide in a dose of $100 \mu \mathrm{g}$ daily may lead to a significant reduction in sputum eosinophils with a larger number of patients treated for a longer period, as the anti-inflammatory effect of inhaled steroids is also time dependent. ${ }^{29}$

Airway inflammation contributes to airway hyperresponsiveness. By suppressing inflammation within the airways, corticosteroids improve asthma control and airway hyperresponsiveness. ${ }^{30}$ The improvement in lung function usually precedes and reaches a plateau before the reduction in airway responsiveness. ${ }^{31}$ The reduction in responsiveness takes place over several weeks and may not be maximum for three months or, in some patients, even longer. ${ }^{32-34}$ The response of $\mathrm{PC}_{20}$ to inhaled steroids is variable between patients, but the average increase is in the order of one or two doubling dilutions. We have shown a dose dependent effect of $\mathrm{PC}_{20}$ to inhaled corticosteroids which is in agreement with previous studies. ${ }^{35}$ A marked increase in methacholine $\mathrm{PC}_{20}$ with budesonide $1600 \mu \mathrm{g}$ was shown but there was no significant change with either $100 \mu \mathrm{g}$ or $400 \mu \mathrm{g}$ budesonide. This implies that the mechanisms underlying airway hyperresponsiveness may be less sensitive to steroid treatment. A greater improvement in $\mathrm{PC}_{20}$ with high dose inhaled steroids has been reported previously. ${ }^{36} \mathrm{PC}_{20}$ may therefore be a less sensitive marker for monitoring the antiinflammatory effects of corticosteroids.

Airway inflammation may not be optimally controlled with current asthma treatment guidelines. ${ }^{3}$ It remains unclear whether a long term complication such as irreversible airway damage can be reduced or prevented if treatment strategy is aimed at suppressing airway inflammation maximally, as guided by sputum eosinophil number or $\mathrm{PC}_{20}$. As $\mathrm{PC}_{20}$ may correlate with features of airway fibrosis, it may be desirable if asthma treatment is directed to normalise $\mathrm{PC}_{20}$. Our findings, however, indicate that higher doses of inhaled steroids may be required to reduce the $\mathrm{PC}_{20}$, thus increasing the risk of systemic side effects. It may be more rational to normalise sputum eosinophil numbers at a lower steroid dose. This may also improve $\mathrm{PC}_{20}$ with chronic treatment. However, this remains to be established in further long term studies.

We conclude that exhaled NO is the most sensitive inflammatory marker for assessing the anti-inflammatory effects of inhaled steroids in steroid naive asthmatic subjects. However, the reduction in exhaled NO following treatment with inhaled steroids may not ensure that airway inflammation is optimally suppressed. This requires an additional assessment of a more direct marker of airway inflammation such as eosinophil number in induced sputum. The clinical usefulness of these markers in the management of asthma remains to be determined.

We thank Astra Draco (Lund, Sweden) for supporting the studies. AJ was in receipt of a research fellowship from the Royal Thai Government, Thailand.

1 NHLBI. Guidelines for diagnosis and management of asthma. NIH Publication No. 97-4051A, 1997:17-47.

2 British Thoracic Society. The British guidelines on asthma management. Thorax 1997;52(Suppl 1):S1-21. 
3 Sont JK, Han J, van Krieken JM, et al. Relationship between the inflammatory infiltrate in bronchial biopsy specimens and clinical severity of asthma in patien

4 Haahtela T, Jarvinen M, Kava T, et al. Effects of reducing or discontinuing inhaled budesonide in patients with mild asthma. N Engl F Med 1994;331:700-5.

5 Kharitonov SA, Yates D, Robbins RA, et al. Increased nitric oxide in exhaled air of asthmatic patients. Lancet 1994;343 $133-5$.

6 Gibson PG, Girgis Gabardo A, Morris, et al. Cellular characteristics of sputum from patients with asthma and chronic bronchitis. Thorax 1989;44:693-9.

7 Kharitonov SA, Yates DH, Barnes PJ. Inhaled glucocorticoids decrease nitric oxide in exhaled air of asthmatic patients. Am f Respir Crit Care Med 1996;153:454-7.

8 Keatings VM, Jatakanon A, Worsdell YM, et al. Effects of in asthma and COPD. Am $\mathcal{f}$ Respir Crit Care Med 1997; 155:542-8.

9 Claman DM, Boushey HA, Liu J, et al. Analysis of induced sputum to examine the effects of prednisone on airway inflammation in asthmatic subjects. $\mathcal{f}$ Allergy Clin Immunol 1994;94:861-9.

10 Jones AH, Langdon CG, Lee PS, et al. Pulmicort Turbohaler once daily as initial prophylactic therapy for asthma. Respir Med 1994;88:293-9.

11 Chai H, Farr RS, Froehlich LA, et al. Standardization of bronchial inhalation challenge procedures. $\mathcal{F}$ Allergy Clin Immunol 1975;56:323-7.

12 Kharitonov SA, Chung KF, Evans D, et al. Increased exhaled nitric oxide in asthma is mainly derived from the lower respiratory tract. Am 7 Respir Crit Care Med 1996;153:1773-80.

13 Jatakanon A, Lim S, Kharitonov SA, et al. Correlation between exhaled nitric oxide, sputum eosinophils, and methacholine responsiveness in patients with mild asthma. Thorax 1998;53:91-5.

14 Armitage P, Berry G. Statistical methods in medical research. Oxford: Blackwell Scientific, 1994: 245-9.

15 Altman DG. Practical statistics for medical research. London: Chapman \& Hall, 1991: 215-7.

16 Gershman NH, Wong HH, Liu JT, et al. Comparison of two methods of collecting induced sputum in asthmatic subjects. Eur Respir 7 1996;9:2448-53

17 in't Veen JC, de Gouw HW, Smits HH, et al. Repeatability of cellular and soluble markers of inflammation in induced sputum from patients with asthma. Eur Respir F 1996;9: 2441-7.

18 Pizzichini E, Pizzichini MM, Efthimiadis A, et al. Indices of airway inflammation in induced sputum: reproducibility and validity of cell and fluid-phase measurements. $A m \mathcal{F}$ Respir Crit Care Med 1996;154:308-17.

19 Pizzichini E, Pizzichini MM, Efthimiadis A, et al. Measuring airway inflammation in asthma: eosinophils and eosinophilic cationic protein in induced sputum compared with peripheral blood. F Allergy Clin Immunol 1997;99:539with

20 Gibson PG, Wong BJ, Hepperle MJ, et al. A research method to induce and examine a mild exacerbation of asthma by withdrawal of inhaled corticosteroid. Clin Exp Allergy 1992;22:525-32.

21 Pizzichini MM, Pizzichini E, Clelland L, et al. Sputum in severe exacerbations of asthma: kinetics of inflammatory indices after prednisone treatment. Am F Respir Crit Care Med 1997;155:1501-8.
22 Lamas AM, Leon OG, Schleimer RP. Glucocorticoids inhibit eosinophil responses to granulocyte-macrophage colony-stimulating factor. F Immunol 1991;147:254-9.

23 Wallen N, Kita H, Weiler D, et al. Glucocorticoids inhibit cytokine-mediated eosinophil survival. I Immunol 1991; 147:3490-5.

24 Hallsworth MP, Litchfield TM, Lee TH. Glucocorticoids inhibit granulocyte-macrophage colony-stimulating inhibit granulocyte-macrophage colony-stimulating human eosinophils. Immunology 1992;75:382-5.

25 Baigelman W, Chodosh S, Pizzuto D, et al. A. Sputum and blood eosinophils during corticosteroid treatment of acute exacerbations of asthma. Am F Med 1983;75:929-36.

26 Corrigan CJ, Hamid Q, North J, et al. Peripheral blood CD4 but not CD8 T-lymphocytes in patients with exacerbation of asthma transcribe and translate messenger RNA encoding cytokines which prolong eosinophil survival in the context of a Th2-type pattern: effect of glucocorticoid therapy. Am f Respir Cell Mol Biol 1995;12:567-78.

27 Busse WW, Chervinsky P, Condemi J, et al. Budesonide delivered by Turbuhaler is effective in a dose-dependent fashion when used in the treatment of adult patients with chronic asthma. F Allergy Clin Immunol 1998;101:457-63.

28 Campbell LM, Gunn SD, Sweeney D, et al. Once daily budesonide: effective control of moderately severe asthma with $800 \mu \mathrm{g}$ once daily inhaled via Turbohaler when compared with $400 \mu \mathrm{g}$ twice daily. Eur F Clin Res 1995;7:1-14.

29 Juniper EF, Kline PA, Vanzieleghem MA, et al. Long-term effects of budesonide on airway responsiveness and clinical asthma severity in inhaled steroid-dependent asthmatics. Eur Respir F 1990;3:1122-7.

30 Barnes PJ. New concepts in the pathogenesis of bronchial hyperresponsiveness and asthma. F Allergy Clin Immunol 1989;83:1013-26.

31 Vathenen AS, Knox AJ, Wisniewski A, et al. Time course of change in bronchial reactivity with an inhaled corticosteroid in asthma. Am Rev Respir Dis 1991;143:1317-21.

32 Juniper EF, Kline PA, Vanzieleghem MA, et al. Effect of long-term treatment with an inhaled corticosteroid (budesonide) on airway hyperresponsiveness and clinical asthma in nonsteroid-dependent asthmatics. Am Rev Respir Dis 1990;142:832-6.

33 van Essen Zandvliet EE, Hughes MD, et al. Effects of 22 months of treatment with inhaled corticosteroids and/or beta-2-agonists on lung function, airway responsiveness, and symptoms in children with asthma. The Dutch Chronic Non-specific Lung Disease Study Group. Am Rev Respir Dis 1992;146:547-54.

34 Kerstjens HA, Brand PL, Hughes MD, et al. A comparison of bronchodilator therapy with or without inhaled corticosteroid therapy for obstructive airways disease. Dutch Chronic Non-Specific Lung Disease Study Group. N Engl f Med 1992;327:1413-9.

35 Kraan J, Koeter GH, van der Mark ?, et al. Dosage and time effects of inhaled budesonide on bronchial hyperreactivity. Am Rev Respir Dis 1988;137:44-8.

36 Booth H, Richmond I, Ward C, et al. Effect of high dose inhaled fluticasone propionate on airway inflammation in sthma. Am f Respir Crit Care Med 1995;152:45-52.

37 Boulet LP, Laviolette $\mathrm{M}$, Turcotte $\mathrm{H}$, et al. Bronchial subepithelial fibrosis correlates with airway responsiveness to methacholine. Chest 1997;112:45-52. 